\title{
ANALISIS SIMULASI PROSES IRONING UNTUK MENGETAHUI KETINGGIAN DINDING BERDASARKAN VARIASI REDUKSI KETEBALAN DINDING
}

\author{
M. Nushron Ali Mukhtar ${ }^{1)}$ dan Sagita Rochman ${ }^{2)}$ \\ ${ }^{1)}$ Program Studi Teknik Industri ; Fakultas Teknologi Industri \\ ${ }^{2}$ Program Studi Elektro ; Fakultas Teknologi Industri \\ Universitas PGRI Adi Buana Surabaya \\ Email: nushron@unipasby.ac.id
}

\begin{abstract}
Abstrak
Proses ironing merupakan salah satu proses metal forming. Aplikasi dari proses ini diantaranya pada proses pembuatan selongsong peluru, dimana ketinggian dari dinding tergantung pada reduksi ketebalan yang digunakan. Pada penelitian ini dilakukan simulasi untuk mengetahui berapakan ketinggian dinding berdasarkan variasi reduksi ketebalan dinding sehingga didapatkan ketinggian yang sesuai dengan kebutuhan dalam pembuatan selonsong peluru. Material yang digunakan untuk selongsong peluru kaliber $20 \mathrm{~mm}$ adalah kuningan Cu30\% Zn 70\% berbentuk cup diameter luar awal 33,5 mm, tebal $3 \mathrm{~mm}$ dan tinggi $37 \mathrm{~mm}$. Berdasarkan perhitungan kekuatan material, maka didapat reduksi ketebalan dinding maksimum yang diijinkan pada proses ironing adalah 26,7\%. Selanjutnya dengan reduksi tersebut dilakukan simulasi menggunakan metode elemen hingga pada variasi sudut die $\alpha=5^{\circ}, 10^{\circ}, 15^{\circ}, 20^{\circ}$ dan $25^{\circ}$. Hasil simulasi proses ironing pada masing-masing sudut die $\alpha$ dan prosentase reduksi ketebalan dinding 26,7\%, menunjukkan, bahwa selongsong peluru belum dapat melawati die. Setelah dilakukan penambahan gaya pada proses simulasi dan dengan variasi reduksi 5\%,10\%,15\%, 20\% dan 25\%, menghasilkan untuk reduksi 5\% :39mm , 10\%: $42 \mathrm{~mm}, 15 \%: 45 \mathrm{~mm}, 20 \%: 51 \mathrm{~mm}$ dan $25 \%: 55 \mathrm{~mm}$.
\end{abstract}

Kata kunci: Simulasi Ironing, Ketinggian Dinding, Reduksi ketebalan dinding

\begin{abstract}
Ironing process is one of the metal forming, the application of this process among others in the process of making bullet case, where the height of the wall depends on the reduction of wall thickness. In this study, a simulation is conducted to find out what is the height of the wall based on the variation reduction of wall thicness so as to obtain the height corresponding to the requirement in making bullet case. The material used for bullet case caliber $20 \mathrm{~mm}$ is brass Cu30\% Zn 70\% early-shaped cup with $33.5 \mathrm{~mm}$ outer diameter, $3 \mathrm{~mm}$ thick and $37 \mathrm{~mm}$ high. Based on material strength calculation, the maximum allowable wall reduction thickness in the ironing process is $26.7 \%$. The simulation is carried out using finite element method on a variety of die corner as $\alpha=5^{\circ}, 10^{\circ}, 15^{\circ}, 20^{\circ}$ and $25^{\circ}$. The results of the simulation of the ironing process at each angle die $\alpha$ and the percentage of wall thickness reduction of $26.7 \%$, indicates, that the bullet casings have not been able to pass the die. After the addition of force on the simulation process and with variation of $5 \%, 10 \%, 15 \%, 20 \%$ and 25\% reduction, yield for 5\%: $39 \mathrm{~mm}, 10 \%: 42 \mathrm{~mm}, 15 \%: 45 \mathrm{~mm}, 20 \%: 51 \mathrm{~mm}$ and $25 \%$ reduction \%: $55 \mathrm{~mm}$.
\end{abstract}

Keywords: Simulation Ironing, high wall, reduction of wall thickness 


\section{PENDAHULUAN}

Pada dasarnya proses ironing sama dengan proses penekan (ekstrusion) untuk memperoleh dimensi tertentu. Proses ironing biasa digunakan untuk pembuatan kaleng minuman berbahan aluminium, silinder bertekanan tinggi, rumah untuk pompa dan rumah untuk shock absorber (Adamovic et al.,2010). Disamping itu proses ironing dapat dimanfaatkan untuk membuat selongsong peluru, seperti terlihat pada gambar 1. Proses ironing diawali dengan membuat bentuk material seperti mangkok silinder/cup, kemudian untuk pembuatan silinder panjang tanpa sambungan dengan cara menekan bagian dalam cup dengan punch, hingga seluruh bagian dari cup dapat keluar dari die. Kampus dkk (Kampus.Z et al.,2002) menggunakan teori plastisitas untuk memodelkan proses ironing, penelitiannya menggunakan diagram kemampuan kerja untuk mendiskripsikan daerah tegangan-regangan. Mereka menggunakan teori tersebut untuk membuat cup dengan bentuk ketebalan dinding yang tidak seragam, pengamatan dilakukan dengan FEM dengan bantuan software untuk mengetahui perubahan gaya.

Menurut Sucy ivana (2006) besarnya reduksi maksimum dalam proses ironing adalah 50\%).

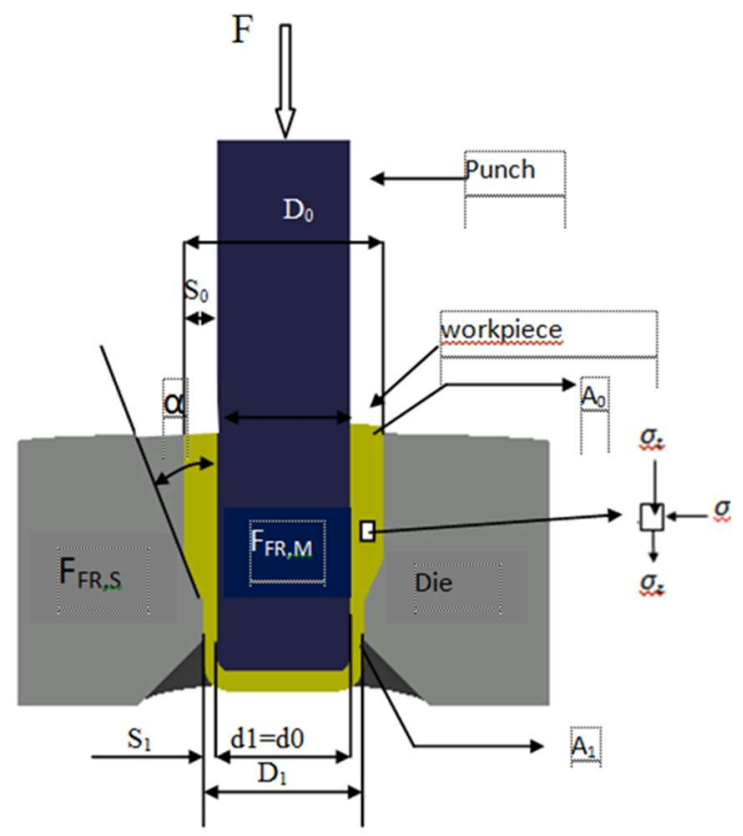

Gambar 1.Skema proses ironing

Wang,Z (2001) memvariasikan prosentase reduksi $5 \%$ sampai $20 \%$ dengan rentang $5 \%$. Beberapa penelitian seperti Adamovic et al.,(2010), Wang.Z (2001) dan Chang, D.
(1998) menetapkan besarnya sudut die $(\alpha)$ pada penelitiannya sebesar $5^{\circ}, 10^{\circ}, 15^{\circ}, 20^{\circ}$ dan $25^{\circ}$.

Pada proses ironing terdapat peristiwa penekanan, dan terjadi penipisan dinding yang dilakukan oleh punch dan dies. Pada dasarnya proses ironing hampir sama dengan proses ekstrusi, kedua proses tersebut sama-sama menyebabkan terjadinya perubahan geometri dengan cara memaksa benda kerja agar masuk ditekan oleh punch pada lubang dies (Suryaningrat, R.,2012). Pada proses ekstrusi, ironing disebut juga dengan forward hollow extrusion (proses ekstrusi bagian luar dengan dimensi material berbentuk tubular) (Schuler.,1998). Oleh karena itu, pada proses ironing dapat dilakukan pendekatan dengan proses forward hollow extrusion.

Tujuan dalam penelitian ini adalah untuk mengetahui ketinggian dinding berdasarkan hasil simulasi yang telah dilakukan, dibandingkan dengan hasil perhitungan, dengan memvariasikan reduksi ketebalan dinding dan sudut ring ironing die. Gaya total ironing $F$ i,tot merupakan penjumlahan dari gaya ideal $\left(\mathrm{F}_{\mathrm{Id}}\right)$, gaya gesek pada die shoulder $\left(\mathrm{F}_{\mathrm{FR}, \mathrm{S}}\right)$, dan gaya geser $\left(\mathrm{F}_{\mathrm{Sh}}\right)$ dikurangi dengan gaya gesek pada mandrel $\left(\mathrm{F}_{\mathrm{FR}, \mathrm{M}}\right)$ (Lange,K., 1985),. Pernyataan tersebut dapat ditulis seperti berikut:

$F_{i, t o t}=F_{i d}+F_{F R, S}-F_{F R . M}+F_{S h}$

Seperti terlihat pada gambar 1, jika masingmasing gaya diatas diuraikan, maka persamaan gaya ironing total adalah sebagai berikut (Schuler : 1998)

$F_{i, t o t}=A_{1} \sigma_{f \cdot m}\left[\left(1+\frac{2 \mu_{s}}{\sin 2 \alpha}-\frac{2 \mu_{M}}{\tan \alpha}\right) \varphi_{\max }+\frac{1}{2} \hat{\alpha}\right]$

Dimana $\mathrm{A}_{1}$ adalah luas penampang setelah ironing, $\sigma_{\mathrm{fm}}$ adalah aliran tegangan rata-rata, $\varphi_{\max }$ adalah Regangan maksimum, $\mu_{\mathrm{S}}$ adalah koefisien gesek pada die shoulder $=0.07, \mu_{\mathrm{M}}$ adalah koefisien gesek pada mandrel dan $\alpha$ adalah sudut die. Karena pendekatan yang dilakukan sesuai dengan proses ekstrusi, dimana gaya gesek yang terjadi adalah penjumlahan dari gaya gesek pada die shoulder dan gaya gesek pada mandrel yang dinyatakan sebagai berikut:

$$
F_{F r}=F_{F R, S}+F_{F R, M}
$$


Apabila persamaan (1) dan (3) digabungkan, maka $\mathrm{F}_{\mathrm{i}, \text { tot }}$ menjadi:

$$
F_{i, t o t}=F_{\text {tot }}+F_{F R, M}=F_{i d}+F_{F R, S}+F_{S h}
$$

Selanjutnya gaya total proses ironing dapat ditulis seperti:

$$
F_{i o t}=A_{1} \sigma_{f . m}\left[\left(1+\frac{2 \mu_{S}}{\sin 2 \alpha}\right) \varphi_{\max }+\frac{1}{2} \hat{\alpha}\right]
$$

Setelah didapatkan nilai reduksi diameter cup pada setiap tahap, maka dilakukan perhitungan ketinggian yang dicapai pada setiap tahapan. Karena pada proses ironing tidak terjadi perubahan pada volume produk, maka ketinggian yang dicapai di setiap tahapan dapat dicari dengan persamaan volume. Ketinggian pada tiap reduksi yang diterapkan tentunya berbeda-beda, semakin besar penipisannya maka akan semakin banyak material yang akan terbawa sehingga ketinggian juga akan semakin bertambah.

Seperti pada gambar 2 berikut dimana volume 1 adalah hasil proses ironing, sedangkan volume 2 adalah berupa lembengan pelat.

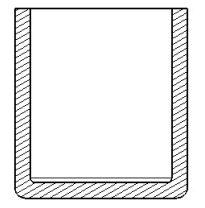

Volume 1

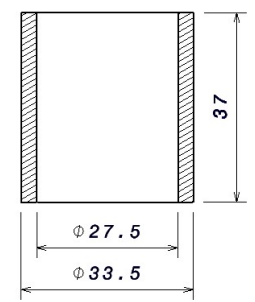

\section{Volume 2}

Gambar 2 Penyederhanaan volume

Persamaan volume 1

$$
V_{1}=\left(\frac{\pi}{4} \times D_{1}^{2} \times L\right)-\left(\frac{\pi}{4} \times d_{1} \times L\right)
$$

Persamaan volume 2

$$
V_{2}=\left(\frac{\pi}{4} \times D_{1}^{2} \times t\right)
$$

Dimana $D_{l}$ adalah diameter cup sebelum ironing dan $\mathrm{D}_{2}$ adalah diameter cup setelah ironing dan $d_{l}$ adalah diameter punch/mandrel. $t$ merupakan tebal pelat sebelum dibentuk cup. Maka total volume adalah:

$V_{\text {tot }}=V_{1}+V_{2}$

sehingga

$$
\text { Vtot }=\left(\frac{\pi}{4} \times D_{1}^{2} \times L\right)-\left(\frac{\pi}{4} \times D_{P}^{2} \times(L-t)\right)
$$

\section{METODE}

Pada proses analisis simulasi, deformasi yang terjadi pada benda kerja, diasumsikan seperti pada kejadian plane strain ( workpiece bersifat(4) flexible), sedangkan untuk Die dan punch bersifat rigid . Punch bergerak ke bawah / searah dengan arah aksial. Material yang digunakan adalah kuningan (brass cartridge). Dengan sifat mekanik dan spesifikasi seperti yang tertulis di dalam tabel. 1 berikut.

Tabel 1. Dimensi Benda Kerja(BK)

\begin{tabular}{l|c|c|c}
\hline \multicolumn{1}{c|}{ Keterangan (BK) } & Simbol & Dimensi & Satuan \\
\hline Tinggi awal & $\mathrm{t}_{0}$ & 37 & $\mathrm{~mm}$ \\
Tebal Awal & $\mathrm{h}_{0}$ & 3 & $\mathrm{~mm}$ \\
Diameter Luar Cup & $\mathrm{D}_{0}$ & 33.5 & $\mathrm{~mm}$ \\
Diameter dalam Cup & $\mathrm{d}_{1}$ & 27.5 & $\mathrm{~mm}$ \\
\hline
\end{tabular}

Tabel 2. Mechanical Properties BK

\begin{tabular}{l|c|c|c}
\hline \multicolumn{1}{c}{ Keterangan (BK) } & Simbol & Nilai & Satuan \\
\hline Young Modulus & $E$ & 110 & $\mathrm{MPa}$ \\
Poisson Ratio & $v$ & 0.35 & \\
Yield Strength & $\sigma$ & 113 & $\mathrm{MPa}$ \\
Density & & 8216 & \\
\hline
\end{tabular}

Tabel 3. Boundary Condition

\begin{tabular}{l|c|c}
\hline \multicolumn{1}{c}{ Keterangan (BK) } & Simbol & Nilai \\
\hline Sudut Ironing Die & $\alpha$ & $5^{\circ}, 10^{\circ}, 15^{\circ}, 20^{\circ}, 25^{\circ}$ \\
Reduksi & $R$ & $5 \%, 10 \%, 15 \%, 20 \%, 25 \%$, \\
Koefisien Reduksi & $\mu$ & 0.07 \\
\hline
\end{tabular}

\section{Penentuan Reduksi Ketebalan Dinding}

Sebagai langkah awal ditentukan reduksi ketebalan dinding selongsong maksimum yang dapat dicapai pada proses ironing. Untuk itu dilakukan perhitungan tegangan yang terjadi pada reduksi mulai $50 \%, 30 \%, 28 \%, 27 \%$ dan $26 \%$, pada setiap perubahan sudut die mulai dari $5^{\circ}, 10^{\circ}, 15^{\circ}, 20^{\circ}$, dan $25^{\circ}$. Selanjutnya tegangan yang terjadi pada setiap variasi sudut die dibandingkan dengan ultimate tensile strength (UTS) material beda kerja. Grafik hasil perhitungan dapat dilihat pada gambar 3. Dari hasil analisa perhitungan, dapat diketahui pada reduksi $26 \%$, material benda kerja masih aman.

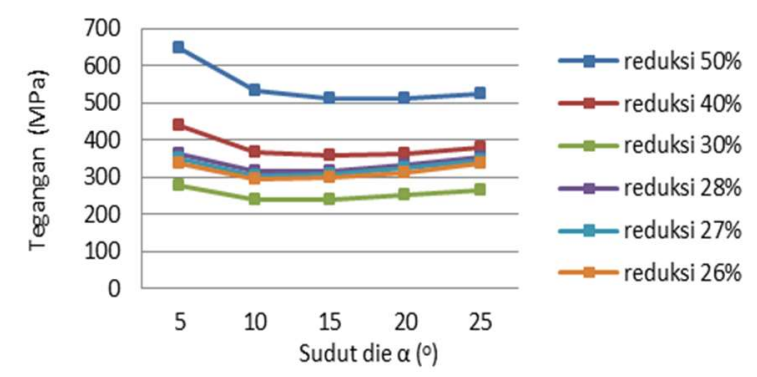

Gambar 3 Grafik tegangan dari hasil perhitungan 
Selanjutnya reduksi dinaikan menjadi $26,7 \%$, dan dihitung secara teoritis besarnya gaya ironing yang dibutuhkan pada sudut die $5^{\circ}$, $10^{\circ}, 15^{\circ}, 20^{\circ}$, dan $25^{\circ}$. Berdasarkan reduksi $26,7 \%$ tegangan yang terjadi pada proses dihitung dan dianalisa, yaitu dibandingkan dengan tegangan material yang diijinkan (UTS). Dari analisa yang dilakukan, dapat diketahui, bahwa tegangan yang

terjadi pada variasi sudut $5^{\circ}$ sampai $25^{\circ}$, lebih kecil daripada UTS material cup. Artinya reduksi maksimal yang memungkinkan proses berhasil adalah dengan reduksi 26,7\%,

Tabel 4 Gaya dan tegangan yang terjadi pada proses ironing

\begin{tabular}{c|c|c|c|c|c}
\hline No & $\begin{array}{c}\text { Die } \\
\text { Angle } \boldsymbol{\alpha} \\
(\mathbf{(})\end{array}$ & $\begin{array}{c}\text { Required } \\
\text { Forming Force } \\
(\mathbf{K n})\end{array}$ & $\begin{array}{c}\text { Result of Stress } \\
\mathbf{( M P a )}\end{array}$ & $\begin{array}{c}\text { Compare } \\
\text { With } \\
\text { UTS }\end{array}$ & Annotation \\
\hline 1 & 5 & 50.01 & 332.25 & $\sigma_{\mathrm{i}}<\sigma$ UTS & Succesfull \\
2 & 10 & 43.46 & 298.65 & $\sigma_{\mathrm{i}}<\sigma$ UTS & Succesfull \\
3 & 15 & 43.91 & 302.57 & $\sigma_{\mathrm{i}}<\sigma \mathrm{UTS}$ & Succesfull \\
4 & 20 & 46.25 & 319.31 & $\sigma_{\mathrm{i}}<\sigma \mathrm{UTS}$ & Succesfull \\
5 & 25 & 49.56 & 335.43 & $\sigma_{\mathrm{i}}<\sigma$ UTS & Succesfull \\
\hline
\end{tabular}

\section{Simulasi Proses Ironing dengan Input Gaya Teoritis.}

Seperti terlihat pada tabel 4, gaya terbesar yang dibutuhkan adalah pada sudut $5^{\circ}$ yaitu 50 $\mathrm{kN}$, sedangkan gaya yang paling kecil dibutuhkan pada sudut $10^{\circ}$, yaitu sebesar 43,46 kN. Selanjutnya gaya-gaya seperti yang tertera pada tabel 2 digunakan sebagai input pada proses simulasi. Simulasi dilakukan dengan menempatkan gaya pada bagian atas punch sesuai dengan besar gaya pada masingmasing sudut die $\alpha$. Punch terletak di dalam cup dan ujungnya bejarak $2 \mathrm{~mm}$ dari dasar bagian dalam cup. Hasil simulasi dapat dilihat pada tabel 3 .

Tabel 5 Hasil simulasi dengan input gaya teoritis

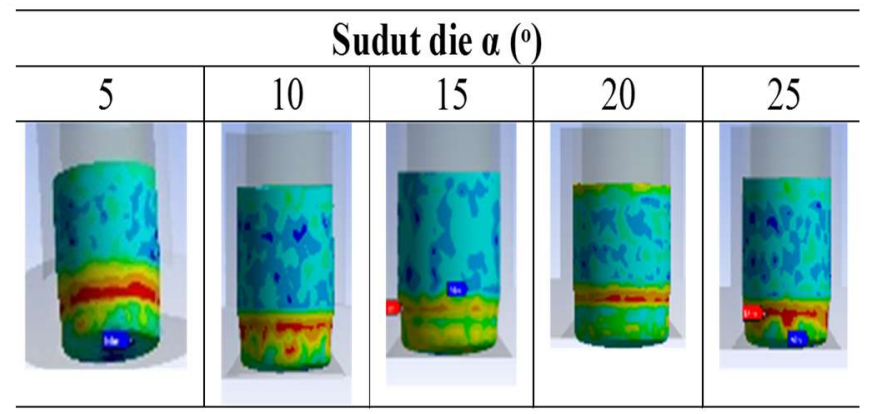

Dari Tabel 5 dapat diketahui, bahwa dengan gaya teoritis, cup belum dapat melewati die. Artinya selongsong belum terbentuk dengan sempurna. Ada 2 alternatif yang mungkin dapat dilakukan, agar proses berjalan baik dan berhasil, yaitu menurunkan reduksi ketebalan dinding atau menaikkan besarnya gaya ironing.

\section{Simulasi Proses Ironing Berdasarkan Perubahan Reduksi Ketebalan Dinding.}

Sesuai dengan proses ironing secara umum reduksi ketebalan dinding diturunkan dari $26,7 \%$ menjadi $5 \%, 10 \%, 15 \% 20 \%$ dan $25 \%$. Dan dengan bantuan software ANSYS dilakukan simulasi proses ironing pada sudut die $\alpha 5^{\circ}, 10^{\circ}, 15^{\circ}, 20^{\circ}$ dan $25^{\circ}$. Hasil simulasi dapat dilihat pada tabel 4.
Dari hasil simulasi dapat diketahui, bahwa proses ironing belum berhasil untuk dapat membentuk cup sampai melewati die. Hal tersebut mungkin disebabkan karena input gaya teoritis belum cukup untuk dapat membentuk cup.

\section{Alternatif Simulasi Proses Ironing dengan Penambahan Gaya.}

Simulasi penambahan gaya dilakukan dengan menambah gaya yang telah dihitung sebelumnya dengan penambahan berturut-turut $5 \%, 10 \%, 50 \%, 100 \%$ dan $200 \%$. Hal ini dilakukan untuk mengetahui berapa besar gaya yang dibutuhkan pada proses ironing mulai dari penekanan awal sampai akhir, hinga cup dapat keluar dari die. 
Hasil simulasi penambahan gaya ironing, menunjukkan bahwa dengan prosentase 5\% belum terjadi perubahan bentuk cup. Cup mulai dapat berubah bentuk pada saat gaya di tambah hingga $50 \%$. Pada sudut $5^{0}$ dan $25^{\circ}$, cup baru dapat melewati die setelah prosentase penambahan gaya $200 \%$, artinya pada sudut $5^{0}$ gaya total yan diberikan mencapai $150,03 \mathrm{kN}$, sedangkan pada sudut $25^{\circ}$ gaya total yang diberikan adalah 148,68 kN.

Tabel 6 Hasil simulasi proses ironing dengan penambahan gaya

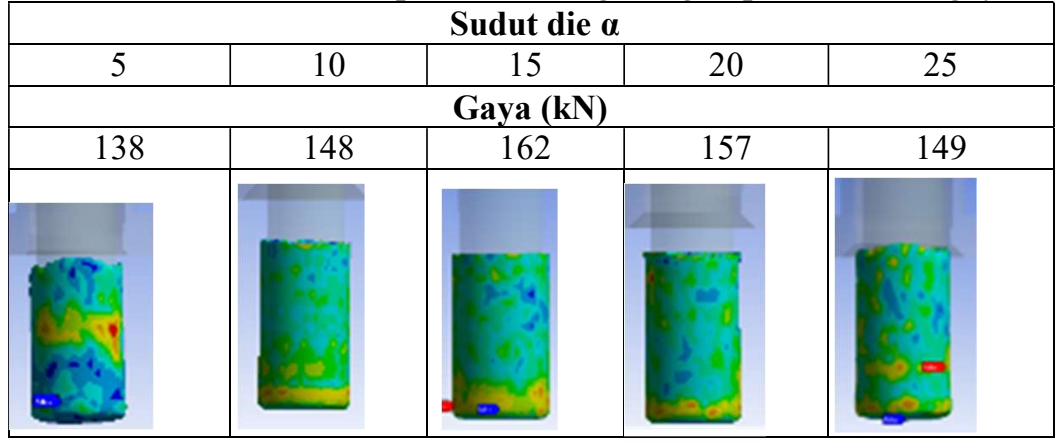

Namun berbeda dengan penambahan gaya pada sudut die lainnya, meskipun dengan penambahan prosentase gaya yang sama, cup belum dapat melewati die. Hal tersebut disebabkan, karena gaya yang diberikan masih kurang besar. Dengan demikian besar gaya yang diperlukan untuk membentuk cup pada kondisi tersebut juga belum dapat diketahui, sehingga pada sudut $\alpha 10^{\circ}, 15^{0}$ dan $20^{\circ}$ perlu dilakukan penambahan prosentase gaya hingga cup dapat melewati die.

\section{PEMBAHASAN}

Berdasarkan perhitungan teoritis untuk variasi reduksi yang digunakan yaitu 5\%, 10\%, 15\% $20 \%$ dan $25 \%$. Didapatkan hasil seperti pada tabel 7 berikut.

Tabel 7 hasil perhitungan ketinggian teoritis berdasarkan veriasi reduksi

\begin{tabular}{r|c|c|c|c}
\hline \multicolumn{5}{c}{ Reduksi (\%) } \\
25 & 20 & 15 & 10 & 5 \\
Perubahan $\boldsymbol{D}_{1}$ dari $\varnothing$ & $\mathbf{3 3 . 5} \mathbf{~ m m}$ ke & \\
$\varnothing 32.105$ & $\varnothing 32.4$ & $\varnothing 32.67$ & $\varnothing 32.95$ & $\varnothing 33.23$ \\
53 & 50 & 47 & 44 & 42 \\
\hline
\end{tabular}

Berdasarkan hasil simulasi diatas jika dibandingkan dengan hasil perhitungan, maka akan terlihat berbeda. Namun perbedaan yang terjadi tidak terlalu jauh. Perbandingan antara hasil simulasi dengan hasil perhitungan ketinggian cup setelah ironing dapat dilihat pada gambar 4 .

Delarbre dan Montmitonnet (1999), melakukan analisis simulasi proses ironing untuk memperoleh ketinggian dan membandingkan hasil simulasi dengan analisis studi. Material yang digunakan adalah aluminium dengan ketebalan awal $0.25 \mathrm{~mm}$ untuk dijadikan cup dengan ketebalan $0.18 \mathrm{~mm}$. Dari hasil penelitian menunjukkan jika hasil analisis studi untuk perhitungan ketinggian dinding lebih lebih besar dari pada hasil simulasi.

Begitu juga dengan penelitian Nam dan Han (2000), yang menganalisis dengan metode analisis elemen hingga/finite element analysis pada material baja untuk pembuatan kaleng minuman. Pada penelitian tersebut juga dibandingkan dengan hasil dari experinment. Dimana hasil dari penelitian menunjukkan bahwa ketinggian hasil teoritis cenderung berubah seiring dengan variasi sudut. Namun berbeda ketika saat simulasi dan hasil eksperimen.

Sedangkan pada penelitian ini adalah seperti pada gambar 4 dibawah ini.

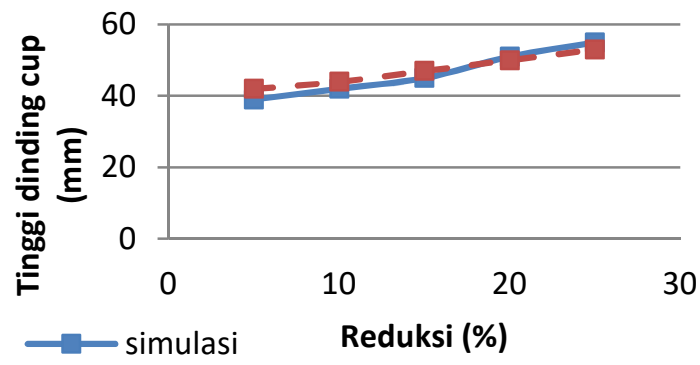


Gambar 4 perbandingan ketinggian dinding hasil teoritis dan simulasi

Dari grafik tersebut menunjukkan bahwa tinggi dinding hasil simulasi lebih tinggi dari pada hasil perhitungan. Pada reduksi 5\% hasil simulasi memang labih rendah, namun saat mencapai reduksi 20\%, hasil dari perhitungan dapat dilampaui, dan pada reduksi 25\% antara keduanya selisih $2 \mathrm{~mm}$. dari hasil ini dapat disimpulakan bahwa baik dengan perhitungan maupun dengan simulasi hasil yang didapatkan tidak jauh berbeda. Oleh karenanya dapat digunakan sebagai acuan dalam menentukan tinggi dinding dari hasil proses ironing. Hasil gambar dari simulasi tinggi dinding dengan reduksi dapat dilihat pada tabel 8

Tabel 8. ketinggian cup Hasil simulasi

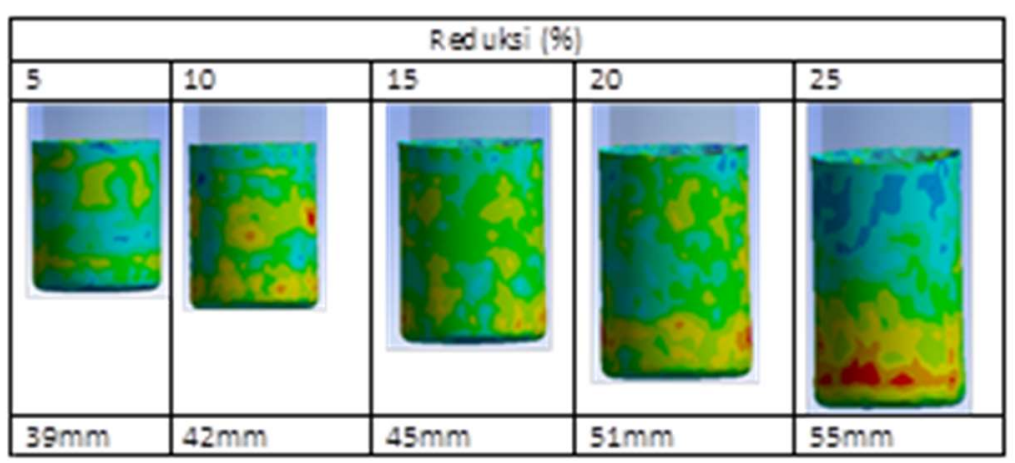

Analisa dan Evaluasi Hasil Simulasi Penambahan Gaya.

Agar didapatkan besar gaya ironing yang minimum, dan selongsong terbentuk dengan sempurna, dilakukan evaluasi terhadap penambahan gaya (Ali mukhtar dkk: 2016). Jika pada sudut $\alpha$ tertentu cup belum keluar dari die, maka dilakukan penambahan gaya hingga cup dapat keluar dari die.

Seperti terlihat pada tabel 6 , pada sudut $5^{0}$, dengan penambahan gaya $200 \%$, cup sudah dapat melewati die. Kemungkinan untuk mendapatkan nilai gaya yang lebih kecil dari prosentase dapat dilakukan, yaitu pada prosentase $175 \%$ atau dengan gaya sebesar 138 $\mathrm{kN}$, ternyata cup sudah dapat melewati die. Disamping itu pada kondisi tersebut tegangan material yang terjadi adalah $336,06 \mathrm{MPa}$, dan berada dibawah UTS material.

Pada sudut $10^{\circ}$, cup baru dapat melewati die pada penambahan gaya $250 \%$. Namun demikian, kemungkinan untuk memperkecil gaya masih dapat dilakukan, yaitu menjadi $240 \%$. Dengan pengurangan tersebut, gaya minimum sudah dapat tercapai, artinya cup sudah dapat melewati die, yaitu sebesar 148
Kn. Tegangan yang terjadi adalah $334,71 \mathrm{MPa}$, dan masih dibawah UTS material.

Penambahan prosentase terbesar terjadi pada sudut $15^{\circ}$, yaitu $270 \%$ atau dengan gaya 163 kN. Namun demikian cup belum terbentuk. Disamping itu tegangan yang terjadi adalah $341,84 \mathrm{MPa}$, lebih besar daripada tegangan ijin material.

Pada sudut $20^{\circ}$ cup berhasil melewati die stelah dilakukan penambahan gaya sebesar 240 $\%$ atau dengan gaya sebesar $157 \mathrm{kN}$. Namun demikian, besarnya tegangan yang terjadi adalah 338,74 Mpa, hampir sama besarnya dengan batas atas tegangan yang diijinkan.

Pada penambahan gaya hingga $200 \%$ atau dengan sudut $\alpha=25^{\circ}$, cup dapat melewati die, tetapi tegangan yang terjadi adalah 345,52 Mpa dan tidak merata.

Berdasarkan atas hasil simulasi diatas, dapat disusun sebuah hasil analisa hasil proses ironing, seperti yang ditunjukkan oleh tabel 9.

Dari tabel 7 terlihat, bahwa pada sudut die $5^{\circ}$ dan $10^{\circ}$ menunjukkan, bahwa hasil simulasi proses ironing berhasil, artinya dapat terbentuk selongsong dengan spesifikasi tertentu.

Tabel 9 Analisis proses ironing pada penambahan gaya pembentukan

\begin{tabular}{c|c|c|c|c|c}
\hline No & $\begin{array}{c}\text { Die } \\
\text { Angle } \\
\boldsymbol{\alpha}(\mathbf{(})\end{array}$ & $\begin{array}{c}\text { Force } \\
\text { Required } \\
(\text { Kn) }\end{array}$ & $\begin{array}{c}\text { Result } \\
\text { of Stress } \\
\text { (MPa) }\end{array}$ & $\begin{array}{c}\text { Comparing } \\
\text { With } \\
\text { UTS }\end{array}$ & Annotation \\
\hline 1 & 5 & 138 & 336.06 & $\sigma_{\mathrm{i}}<$ UTS & Succesfull \\
2 & 10 & 148 & 334.71 & $\sigma_{\mathrm{i}}<$ UTS & Succesfull \\
3 & 15 & 162 & 341.48 & $\sigma_{\mathrm{i}}<$ UTS & Unsuccesfull \\
4 & 20 & 157 & 338.74 & $\sigma_{\mathrm{i}}<$ UTS & Succesfull \\
5 & 25 & 149 & 345.52 & $\sigma_{\mathrm{i}}<$ UTS & Unsuccesfull \\
\hline
\end{tabular}


Disamping itu pada kedua kondisi tersebut tegangan maksimum material (UTS) yang diijinkan lebih kecil daripada tegangan yang terjadi. Sebaliknya pada sudut $15^{\circ}, 20^{\circ}$, dan $25^{\circ}$, tegangan yang terjadi lebih besar daripada tegangan material yang diijikan, sehingga pada kondisi tersebut dapat dinyatakan proses ironing gagal(Adamović et all:2009). Berdasarkan analisis ketinggian hasil simulasi menunjukkan pada reduksi $20 \%$ dan $25 \%$ didapatkan hasil yang lebih tinggi dari hasil perhitungan teoritis.

\section{KESIMPULAN}

Berdasarkan perhitungan gaya pembentukan pada selonsong peluru kaliber 20 mm, dengan material $\mathrm{Cu}$ Zn 7--30 dapat diketahui bahwa reduksi maksimal ketebalan dinding adalah 26,7\%. Dengan gaya pembentukan sebesar $138 \mathrm{kN}$ pada sudut $5^{\circ}$, dan $148 \mathrm{kN}$ pada sudut $10^{\circ}$ dapat disimpulkan proses ironing berhasil, yaitu benda kerja dapat keluar melewati die, tegangan maksimum yang terjadi pada kedua kondisi tersebut lebih kecil daripada tegangan maksimum material (UTS) benda kerja. Berdasarkan variasi reduski yang diterapkan, dapat dilihat bahwa ketinggian cup hasil simulasi menujukkan tingkat perbedaan pada sudut $20^{\circ}$ dan $25^{\circ}$ yaitu $51 \mathrm{~mm}$ dan $55 \mathrm{~mm}$.

\section{UCAPAN TERIMA KASIH}

Penelitian ini telah mendapatkan dukungan dari dekan, ketua jurusan Teknik Industri, dan teknik elektro. kepala laboratorium Teknik Industri Universitas PGRI Adi Buana Surabaya atas kesadiaanya memfasilitasi penelitian ini di ruang laboratorium multi media.

\section{DAFTAR PUSTAKA}

Adamovic, D., Mandic, V., Jurkovic, Z., dkk. (2010), “An Experimental Modelling And Numerical FE Analysis Of Steel-Strip Ironing Process", Vol. 4, Hal. 435 - 444.

Adamović, D.,Stefanović, M, Gulišija Z., Aleksandrović, S., Živković, M., Devedžić, G., (2009), "Changing Of Tension Stress Of Ironed Aluminium Work Piece Wall "., Journal for Technology of Plasticity, Vol. 34 Number 1-2.

Chang, D. (1998), “ An analytical model of ironing process including redundant work effect”, Journal of Materials Processing Technology 75 (1998) 253-258

Delarbre, D., Montmitonne, P. (1999), "Experimental and numerical study of the ironing of stainless steelCups", Journal of Materials Processing Technology 91, 95 - 104

Nam, J., Han K, S.,(2000)," Finite Element Analysis of Deep Drawing and Ironing Process in the Steel D \& I Can making”, ISIJ International, Vol. 40 (2000), No. 12, pp. 1223-1229.

Kampus, Z. and Nardin, B. "Improving workability in ironing", Journal of Materials Processing Technology 130-131 (2002) 64-68

Lange Kurt, (1985), Handbook of Metal Forming, Mc Graw-Hill inc, Michigan

Mukhtar Ali, M. N., I. M. L. Batan, B. Pramujati, A. S. Pramono., (2016),Simulation of Ironing Process for Bullet Case to Get Minimum Forming Force with Variation of Die Angle and Reduction Wall Thickness, Applied Mechanics and Materials, Vol. 836, pp. 197-202.

Sucy Ivana, (2006), Handbook Of Die Design, $2^{\text {nd }}$ edition, Mc Graw-Hill. New york

Suryaningrat, Rianto . (2012), Intellegence Precise Manufacturing ( Ironing Process)., BBPT.

Schuler. (1998), Metal Forming Handbook (c) Springer-Verlag Berlin Heidelberg

Wang, Z., Dohda, K., Jeong, Y. (2001)," FEM simulation of surface smoothing in the ironing process", Journal of Materials Processing Technology 113 (2001) 705-709. 